\title{
Type 2 Autoimmune Polyglandular Syndrome Presenting with Hyperpigmentation and Amenorrhea
}

\author{
Nayana Gaba ${ }^{1}$, Saurabh Gaba ${ }^{2}$, Mandeep Singla ${ }^{2}$, Monica Gupta ${ }^{3}$ \\ 1. Obstetrics and Gynaecology, Postgraduate Institute of Medical Education and Research, Chandigarh, IND 2. Internal \\ Medicine, Government Medical College and Hospital, Chandigarh, IND 3. General Medicine, Government Medical \\ College and Hospital, Chandigarh, IND
}

Corresponding author: Saurabh Gaba, sgaba165@gmail.com

\begin{abstract}
A 36-year-old female presented with lethargy, anorexia, nausea, hyperpigmentation, weight loss and amenorrhea for six months. On examination, she had hyperpigmentation of face, hands and oral mucosa. Investigations revealed adrenal insufficiency and subclinical hyperthyroidism with elevated anti-thyroid peroxidase antibodies. Adrenal insufficiency in combination with Grave's disease and/or type 1 diabetes mellitus occurs in type 2 autoimmune polyglandular syndrome. It is a polygenic disorder occurring due to mutations in the human leukocyte antigen complex on chromosome 6. The patient was treated with oral hydrocortisone which led to improvement in all the symptoms.
\end{abstract}

Categories: Internal Medicine, Obstetrics/Gynecology

Keywords: autoimmune polyglandular syndrome, schmidt syndrome, adrenal insufficiency, amenorrhea, aps

\section{Introduction}

Autoimmune polyglandular syndromes (APS) are a group of disorders that share a common genetic alteration that lead to dysfunction of multiple endocrine organs. These may be associated with a host of other autoimmune conditions. Autoimmunity can affect the adrenals, thyroid, pancreas, parathyroid glands, liver, gonads, skin and gastric mucosa [1]. The involvement of different organs can either be subtle and subclinical or it may be overt, leading to early diagnosis. Herein, the case of a middle-aged female with type 2 APS is presented. She had adrenal insufficiency, for which oral hydrocortisone was started, and subclinical Grave's disease for which a wait and watch policy was adopted.

Received 04/10/2020 Review began 04/14/2020 Review ended 04/14/2020 Published 04/21/2020

○) Copyright 2020 Gaba et al. This is an open access article distributed under the terms of the Creative Commons Attribution License CC-BY 4.0., which permits unrestricted use, distribution, and reproduction in any medium, provided the original author and source are credited.

\section{Case Presentation}

A 36-year-old female presented to the outpatient department with a history of anorexia, nausea, lethargy, undue fatigue, hyperpigmentation of skin and weight loss. The symptoms appeared over a period of months and worsened gradually to the point where she was unable to carry out her daily activities without assistance. She had amenorrhea for six months and occasional diarrhea without blood or nocturnal awakening. There was no history of chest pain, palpitations and shortness of breath. On examination, she was afebrile with a blood pressure of $108 / 70 \mathrm{mmHg}$ and a regular pulse of 85 beats per minute. She had conspicuous hyperpigmentation of face, oral mucosa, dorsum of hand and palmar creases (Figures 1-3). 


\section{Cureus}

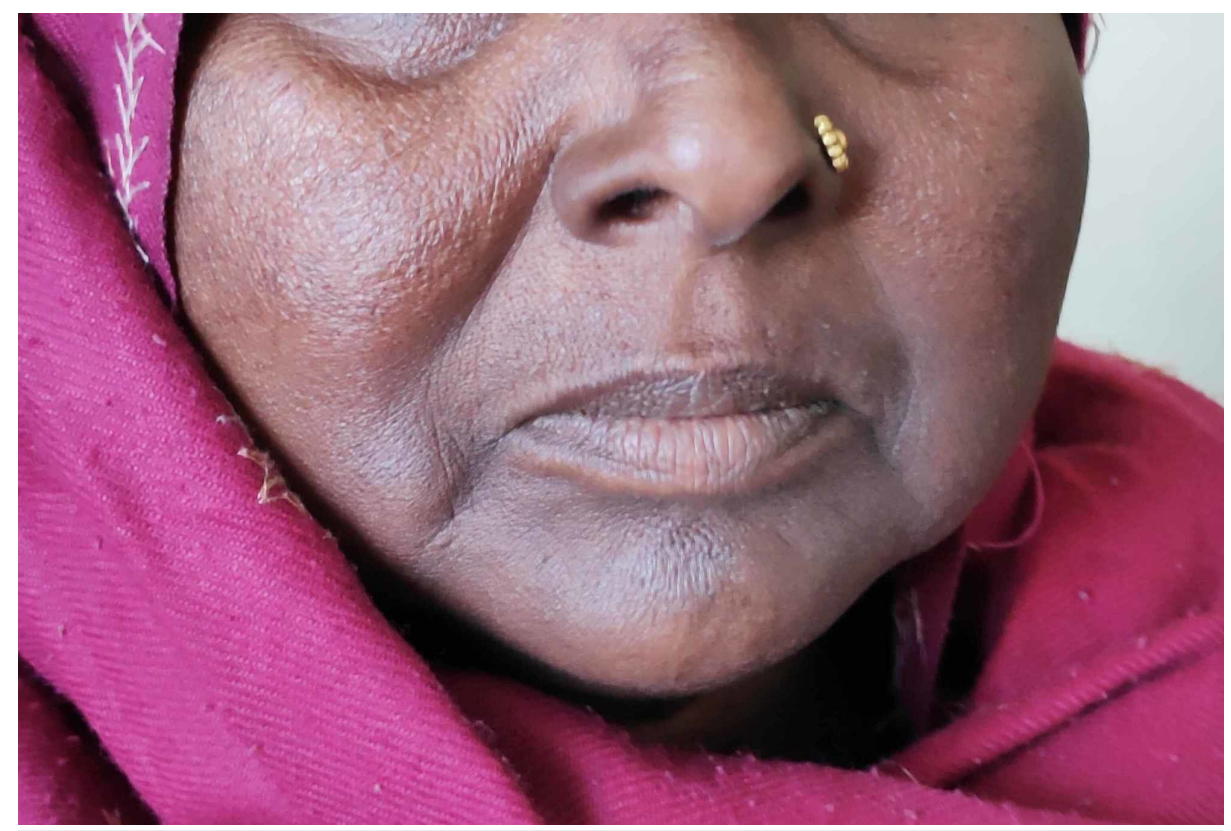

FIGURE 1: Hyperpigmentation of the face, more marked in the perioral region. 


\section{Cureus}

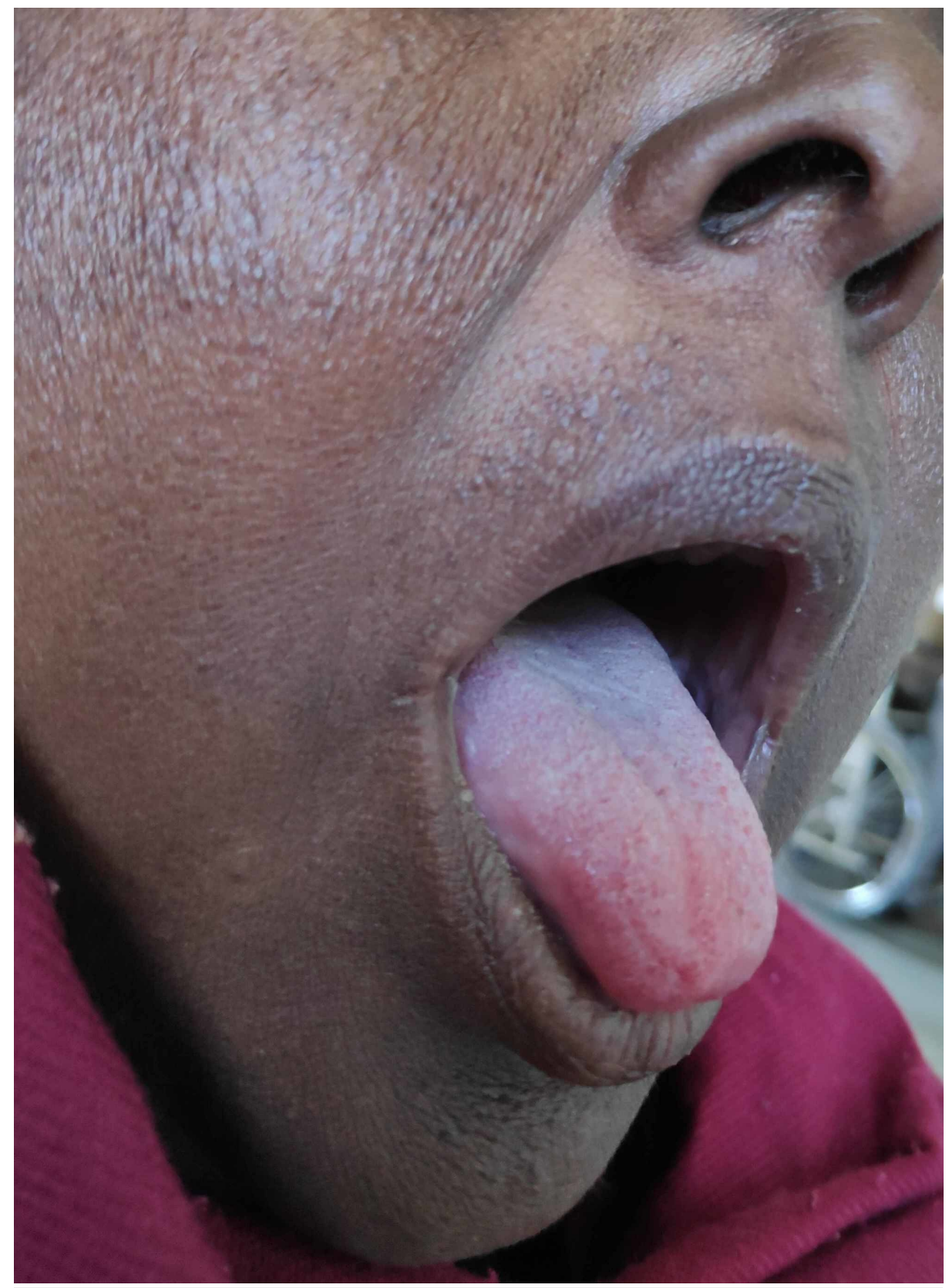

FIGURE 2: Hyperpigmentation of the tongue and buccal musoca. 


\section{Cureus}

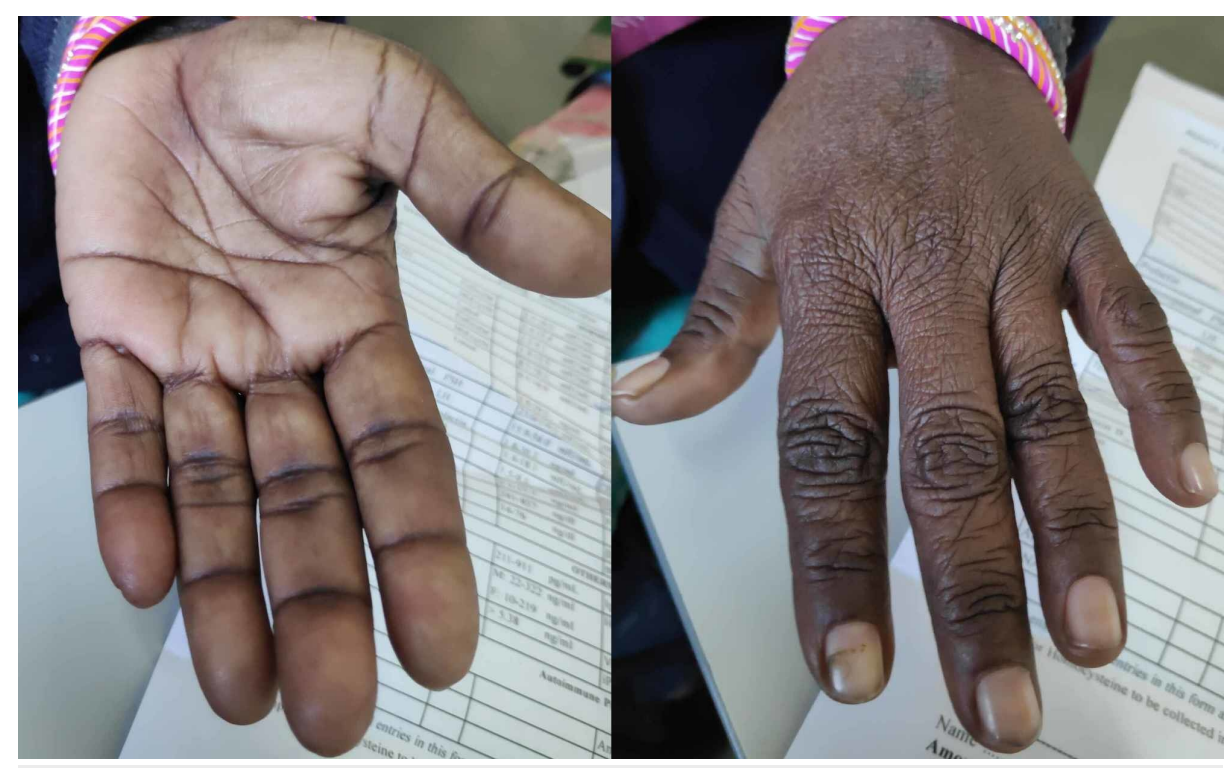

FIGURE 3: Hyperpigmentation of the palmar creases and dorsum of hands.

Respiratory, abdominal and cardiovascular examinations were unremarkable, and she did not have goiter or ophthalmopathy. Investigations revealed subclinical thyrotoxicosis with elevated anti-thyroid peroxidase antibody (anti-TPO) and low fasting cortisol with high concurrent adrenocorticotropic hormone (ACTH) (Table 1). Oral hydrocortisone replacement was started with thrice daily dosing: $7.5 \mathrm{mg}$ in morning, $2.5 \mathrm{mg}$ in afternoon and $2.5 \mathrm{mg}$ in evening. This resulted in drastic symptomatic improvement. Menstural cycles also normalized with treatment, suggesting that amenorrhea was due to adrenal insufficiency per se, rather than hypogonadism. 


\section{Cureus}

\begin{tabular}{|c|c|c|}
\hline Investigation & Value & Normal range \\
\hline Sodium (mmol/L) & 133 & 135-145 \\
\hline Potassium (mmol/L) & 4.7 & $3.5-5.5$ \\
\hline Urea (mg/dL) & 32 & $15-40$ \\
\hline Creatinine (mg/dL) & 1.2 & $<1.3$ \\
\hline Hemoglobin (g/dL) & 12.9 & 13-15 \\
\hline Platelets (X10^9/L) & 230 & $150-400$ \\
\hline Total leukocyte count (X10^9/L) & 6.4 & 4-12 \\
\hline AST (U/L) & 37 & $10-40$ \\
\hline ALT (U/L) & 41 & $10-40$ \\
\hline Morning cortisol (nmol/L) & 67 & $200-600$ \\
\hline Morning ACTH (pmol/L) & 321 & $<80$ \\
\hline TSH (mlU/L) & 0.3 & $0.5-5$ \\
\hline Free T3 (pg/dL) & 440 & $260-480$ \\
\hline Free T4 (ng/dL) & 1.7 & $0.7-1.8$ \\
\hline Anti-TPO (IU/mL) & $>1000$ & $<35$ \\
\hline $\mathrm{LH}^{*}(\mathrm{IU} / \mathrm{L})$ & 63 & $1-70$ \\
\hline FSH* (IU/L) & 7.2 & $2.5-10$ \\
\hline Estradiol* $^{*}(\mathrm{pg} / \mathrm{mL})$ & 76 & $30-400$ \\
\hline Progesterone* (ng/mL) & 2.4 & $0.5-20$ \\
\hline Prolactin (ng/mL) & 27 & $2-25$ \\
\hline HbA1c & $5.3 \%$ & $<6 \%$ \\
\hline
\end{tabular}

\section{TABLE 1: Clinical investigations.}

AST, aspartate transaminase; ALT, alanine transaminase; ACTH, adrenocorticotropic hormone; TSH, thyroid-stimulating hormone; T3, triiodothyronine; T4, tetraiodothyronine; TPO, thyroid peroxidase; $\mathrm{LH}$, luteinizing hormone; FSH, follicular-stimulating hormone; HbA1c, glycated hemoglobin.

*Level depends on the phase of menstural cycle. Levels near the upper limit are seen in the perimenstural period.

\section{Discussion}

\section{Adrenal insufficiency}

The most common cause of primary adrenal insufficiency or Addison's disease in developed countries is autoimmune adrenalitis, while that in developing countries is tuberculosis [2]. The other causes include abrupt withdrawal of corticosteroid therapy, metastases, fungal infections, adrenal infarction and adrenoleukodystrophy. In patients with a reduced adrenal reserve, antifungal drugs such as fluconazole and ketoconazole, opiates such as morphine and tramadol, and anesthetic drug etomidate can also precipitate clinical adrenal insufficiency [3]. The clinical features of acute and chronic adrenal insufficiency are summarized in Table 2 [4]. The biochemical hallmarks are hyponatremia, hyperkalemia and less commonly, hypoglycemia and hypercalcemia. Hyperpigmentation is a virtually universal finding in adrenal insufficiency. It occurs due to excessive synthesis of melanin in response to increased production of melanocyte-stimulating hormone (MSH) [5]. MSH is formed by cleavage of proopiomelanocortin (POMC), a prohormone that is also a precursor of ACTH. Cortisol deficiency amplifies the production of POMC in the pituitary gland. 


\section{Cureus}

\section{Chronic adrenal insufficiency}

Anorexia, nausea, vomiting, abdominal pain

Weight loss

Fatigue

Skin and mucosal hyperpigmentation

Hypotension

Salt craving

Mood disorders, psychosis

Loss of libido

Amenorrhea

\section{Acute adrenal insufficiency (adrenal crisis)}

Hypotension and shock

Anorexia, nausea, vomiting, abdominal pain

Fever

Confusion, delirium, coma

TABLE 2: Clinical features of adrenal insufficiency.

A high serum ACTH level in the setting of low cortisol suggests that the pituitary gland is functioning appropriately and rules out secondary adrenal insufficiency. The gold standard for diagnosis of adrenal insufficiency is ACTH stimulation test which displays an inadequate elevation of cortisol 30 minutes after an intravenous or intramuscular administration of a standard dose of ACTH [6].

Adrenal crisis is potentially fatal, and requires prompt administration of intravenous fluids and hydrocortisone bolus of $100 \mathrm{mg}$ followed by $50 \mathrm{mg}$ six hourly [7]. The preferred regime for chronic adrenal insufficiency is oral hydrocortisone taken in three divided doses, with around half of the total dose taken in morning to mimic the natural circadian rhythm of cortisol [8]. Total daily dose of 10-15 $\mathrm{mg}$ is generally required and the dose is titrated according to the symptoms. Fludrocortisone is usually not required as hydrocortisone itself possesses some intrinsic mineralocorticoid activity.

\section{Grave's disease}

Grave's disease is the most common cause of thyrotoxicosis and is characterized by hyperthyroidism, a diffuse goiter and ophthalmopathy. Less common features are localized dermopathy (pretibial myxedema) and thyroid acropachy (clubbing). The ophthalmopathy can be serious enough to cause blindness by optic nerve compression and exposure keratitis. Excess glycosaminoglycan production by fibroblasts mediated by thyroid-stimulating hormone receptor stimulation in the extraocular tissues leads to proptosis and complex ophthalmoplegia [9]. A CT scan may sometimes be indicated to better visualize the retro ocular tissues and determine appropriate management. The ophthalmopathy follows its own independent clinical course, irrespective of the thyroid status [10]. Smoking and use of radioiodine therapy can exacerbate the eye disease [11].

Treatment of Grave's disease involves control of thyrotoxicosis by thionamides (carbimazole, methimazole and propylthiouracil), radioiodine therapy or surgery [12]. Carbimazole and methimazole are preferred due to once a day dosing, more rapid achievement of euthyroid status and lesser hepatotoxicity. Propylthiouracil is preferred in thyroid storm and in early pregnancy. Early symptomatic relief from sympathetic symptoms is achieved by the use of propranolol, a non-selective beta-blocker. Eye disease requires use of topical lubricants, eye patch and dark glasses. Severe ophthalmopathy requires corticosteroids and surgical debulking. Anti-thyroid treatment is warranted in subclinical thyrotoxicosis only under circumstances such as symptomatic disease, presence of osteoporosis, atrial fibrillation or infertility and age more than 65 years [13].

\section{Autoimmune polyglandular syndromes}

Clustering of autoimmune phenomena within an individual and within a family is well known. This is best exemplified by autoimmune adrenalitis. In a case series, $47 \%$ of patients with adrenal insufficiency due to autoimmune adrenalitis were found to have another coexisting autoimmune disorder [14]. These included hypothyroidism, Grave’s disease, pernicious anemia, Sjögren’s syndrome, vitiligo, hypoparathyroidism, type 1 diabetes mellitus, coeliac disease and premature menopause. A comparison of APS 1 and 2 is shown in Table 3 [1]. Occurrence of hypoglycemia in a patient with previously well-controlled type 1 diabetes is highly suggestive of APS 2. 


\section{Cureus}

\begin{tabular}{|c|c|c|}
\hline & APS 1 & APS 2 (Schmidt syndrome) \\
\hline Diagnosis & $\begin{array}{l}\text { Two of the following: mucocutaneous candidiasis, } \\
\text { hypoparathroidism, adrenal insufficiency }\end{array}$ & $\begin{array}{l}\text { Adrenal insufficiency with autoimmune thyroid disease } \\
\text { (hypothyroidism or Grave's disease) and/or type } 1 \\
\text { diabetes mellitus }\end{array}$ \\
\hline $\begin{array}{l}\text { Other } \\
\text { associations }\end{array}$ & $\begin{array}{l}\text { Type } 1 \text { diabetes mellitus, hypothyroidism, hypogonadism, } \\
\text { pernicious anemia, autoimmune hepatitis, alopecia, vitiligo, } \\
\text { ectodermal dysplasia }\end{array}$ & $\begin{array}{l}\text { Celiac disease, vitiligo, alopecia, myasthenia gravis, } \\
\text { pernicious anemia, IgA deficiency, hypogonadism, } \\
\text { autoimmune hepatitis }\end{array}$ \\
\hline Cause & Mutations in the AlRE gene on chromosome 21 & $\begin{array}{l}\text { Mutations in DQ and DR regions of HLA complex on } \\
\text { chromosome } 6\end{array}$ \\
\hline Inheritance & Autosomal recessive & Polygenic \\
\hline $\begin{array}{l}\text { Peak } \\
\text { prevalence } \\
\text { age }\end{array}$ & S-10 years & 20-40 years \\
\hline $\begin{array}{l}\text { Sex } \\
\text { distribution }\end{array}$ & Male $=$ Female & Female $>$ Males \\
\hline Incidence & $<1$ per $100,000 /$ year & $1-2$ per $10,000 /$ year \\
\hline
\end{tabular}

\section{TABLE 3: Differences between APS 1 and 2.}

APS, autoimmune polyglandular syndrome; AIRE, autoimmune regulator; HLA, human leukocyte antigen.

The treatment depends on the manifestations. Hormone replacement, anti-thyroid drugs and immunosuppression are used as indicated. It is essential is avoid treating hypothyroidism alone in the presence of adrenal insufficiency, as it can precipitate adrenal crisis due to enhanced corticosteroid metabolism in liver [15]. Antifungal drugs and supplementation with calcium and vitamin D are indicated in APS 1.

\section{Conclusions}

This report describes a 36-year-old female with amenorrhea accompanied by obvious signs and symptoms of Addison's disease, which was confirmed on investigations. The presence of subclinical Grave's disease pointed toward a diagnosis of APS 2. Normal HbA1c and sex hormones ruled out concurrent diabetes and hypogonadism. Oral hydrocortisone was started with thrice a day dosing, and she experienced marked symptomatic improvement with correction of amenorrhea. APS 2 comprises of adrenal insufficiency with either or both of type 1 diabetes mellitus and autoimmune thyroid disease. Both types of APS are associated with a variety of other autoimmune disorders that need to be carefully sought and treated.

\section{Additional Information \\ Disclosures}

Human subjects: Consent was obtained by all participants in this study. Conflicts of interest: In compliance with the ICMJE uniform disclosure form, all authors declare the following: Payment/services info: All authors have declared that no financial support was received from any organization for the submitted work. Financial relationships: All authors have declared that they have no financial relationships at present or within the previous three years with any organizations that might have an interest in the submitted work. Other relationships: All authors have declared that there are no other relationships or activities that could appear to have influenced the submitted work.

\section{References}

1. Kahaly GJ, Frommer L: Polyglandular autoimmune syndromes. J Endocrinol Invest. 2018, 41:91-98. 10.1007/s40618-017-0740-9

2. Chabre O, Goichot B, Zenaty D, Bertherat J: Group 1. Epidemiology of primary and secondary adrenal insufficiency: prevalence and incidence, acute adrenal insufficiency, long-term morbidity and mortality. Ann Endocrinol. 2017, 78:490-494. 10.1016/j.ando.2017.10.010

3. Bornstein SR, Bornstein TD, Andoniadou CL: Novel medications inducing adrenal insufficiency . Nat Rev Endocrinol. 2019, 15:561-562. 10.1038/s41574-019-0248-9

4. Erichsen MM, Løvås K, Skinningsrud B, et al.: Clinical, immunological, and genetic features of autoimmune primary adrenal insufficiency: observations from a Norwegian registry. J Clin Endocrinol Metab. 2009, 94:4882-4890. 10.1210/jc.2009-1368 
5. Barnett AH, Espiner EA, Donald RA: Patients presenting with Addison's disease need not be pigmented . Postgrad Med J. 1982, 58:690-692. 10.1136/pgmj.58.685.690

6. Dickstein G, Shechner C, Nicholson WE, et al.: Adrenocorticotropin stimulation test: effects of basal cortisol level, time of day, and suggested new sensitive low dose test. J Clin Endocrinol Metab. 1991, 72:773-778. 10.1210/jcem-72-4-773

7. Dineen R, Thompson CJ, Sherlock M: Adrenal crisis: prevention and management in adult patients [Epub ahead of print]. Ther Adv Endocrinol Metab. 2019, 10.1177/2042018819848218

8. Bornstein SR, Allolio B, Arlt W, et al.: Diagnosis and treatment of primary adrenal insufficiency: an endocrine society clinical practice guideline. J Clin Endocrinol Metab. 2016, 101:364-389. 10.1210/jc.20151710

9. Eckstein AK, Plicht M, Lax H, et al.: Thyrotropin receptor autoantibodies are independent risk factors for Graves' ophthalmopathy and help to predict severity and outcome of the disease. J Clin Endocrinol Metab. 2006, 91:3464-3670. 10.1210/jc.2005-2813

10. Suzuki N, Noh JY, Kameda T, et al.: Clinical course of thyroid function and thyroid associated ophthalmopathy in patients with euthyroid Graves' disease. Clin Ophthalmol. 2018, 12:739-746. 10.2147/OPTH.S158967

11. Khong JJ, Finch S, De Silva C, et al.: Risk factors for Graves' orbitopathy; the Australian Thyroid-associated Orbitopathy Research (ATOR) study. J Clin Endocrinol Metab. 2016, 101:2711-2720. 10.1210/jc.2015-4294

12. Prasek K, Płazińska MT, Królicki L: Diagnosis and treatment of Graves' disease with particular emphasis on appropriate techniques in nuclear medicine. General state of knowledge. Nucl Med Rev Cent East Eur. 2015, 18:110-116. 10.5603/NMR.2015.0026

13. Palacios SS, Pascual-Corrales E, Galofre JC: Management of subclinical hyperthyroidism. Int J Endocrinol Metab. 2012, 10:490-496. 10.5812/ijem.3447

14. Zelissen PM, Bast EJ, Croughs RJ: Associated autoimmunity in Addison's disease . J Autoimmun. 1995, 8:121130. 10.1006/jaut.1995.0009

15. Davis J, Sheppard M: Acute adrenal crisis precipitated by thyroxine. Br Med J. 1986, 292:1185-1186. 10.1136/bmj.292.6529.1185 